\title{
Absence of Mannose in the Extracellular Polysaccharide of Fast-growing Rhizobia
}

\author{
By BEVERLEY HUMPHREY, MARGARET EDGLEY \\ AND J. M. VINCENT \\ School of Microbiology, University of New South Wales, \\ Kensington, N.S.W. 2033, Australia
}

(Received I2 September 1973)

\section{INTRODUCTION}

In a recent study of extracellular polysaccharides of rhizobia, including 43 fast-growing strains, Bailey, Greenwood \& Craig(I97I) found a high incidence and often a high concentration of mannose. That this sugar appeared to be a constituent of exopolysaccharides of fast-growing rhizobia was an unusual finding in that these bacteria have otherwise been found to contain (with methyl, acetyl and pyruvyl substituents) only glucose, galactose and glucuronic acid (Humphrey \& Vincent, 1959; Dudman, 1964; Armarger, Obaton \& Blachère, 1967; Dudman \& Heidelberger, 1969; Björndal et al. I97I ; Zevenhuisen, I97I ; Hepper, 1972). The last was in low concentration, or undetectable, in the extracellular polysaccharides of Rhizobium meliloti. The presence of yeast extract in the medium used by Bailey et al. (1971) and the lack of further purification (other than dialysis) after precipitation of the culture supernatant in three volumes of alcohol, raise the possibility that the source of mannose in their case was not the extracellular polysaccharide itself but a contaminant from the medium, perhaps yeast mannan. Mannose reported for the extracellular polysaccharides of fast-growing rhizobia studied by Clapp \& Davis (1970) might be similarly explained (see Zevenhuisen, I97I). In this connexion it is interesting to note that Björndal et al. (I97I), unlike Clapp \& Davis, successfully used the cetyltrimethylammonium ion to fractionate the extracellular product from a yeast extract broth supernatant of $R$. meliloti into an acidic fraction containing glucose, galactose and pyruvate and a neutral fraction consisting mainly of mannose. The latter again could be expected to have had its origin in yeast mannan.

To investigate this possibility we have analysed again the exopolysaccharides from two strains previously studied by us (Humphrey \& Vincent, 1959) and reported by Bailey et al. (1971) as having contained mannose. Several culture media and purification steps were used, and the sugar analysis employed was the most sensitive at our disposal, the gas-liquid chromatography of alditol acetate derivatives.

\section{METHODS}

Organisms. Rhizobium trifolii strain TAI and R. meliloti SU47, from the Sydney University collection, were used.

Preparation of exopolysaccharide. Cultures were grown for Io days at $26^{\circ} \mathrm{C}$ in either yeast mannitol broth ( $0.4 \%$ Difco yeast extract; Vincent, 1970) or in a defined medium (Vincent, I962) containing mineral salts, thiamin, biotin and either mannitol ( $1 \%$ ) or glucose (I \%) as carbon source. The cultures were diluted with an equal volume of water, centrifuged for $30 \mathrm{~min}$ at $12000 \mathrm{~g}$ and the supernatant spun again to remove all cells. The supernatant was 
then precipitated in $3 \mathrm{vol}$. alcohol, and the precipitated exopolysaccharide dialysed for 2 to 3 days at $4{ }^{\circ} \mathrm{C}$ against three changes of distilled water. A portion of this 'unpurified' exopolysaccharide was removed and lyophilized; then the bulk of the exopolysaccharide was deproteinized by two cycles of Sevag treatment (Sevag, Lackman \& Smollens, I938) and finally precipitated twice more with three volumes of alcohol. This product was lyophilized and stored as 'purified' exopolysaccharide.

Preparation of alditol acetates from sugars. Ampoules containing 8 to $\mathrm{I}$ mg exopolysaccharide and $1.4 \mathrm{ml} \mathrm{N}-\mathrm{HCl}$ (prepared from redistilled $\mathrm{HCl}$ ) were gassed vigorously for 5 min with nitrogen, sealed and heated at $100{ }^{\circ} \mathrm{C}$ for $\mathrm{I} 6 \mathrm{~h}$. The hydrolysate was passed through a bed of Dowex AG $50 \mathrm{~W} \times \mathrm{I} 2\left(\mathrm{Na}^{+}\right)$and the sugars reduced overnight with $\mathrm{I} 0 \mathrm{mg}$ sodium borohydride. The excess borohydride was destroyed by acidification with I $\mathrm{N}-\mathrm{HCl}$, and the contents of the ampoule lyophilized. The residue was taken up in $2 \mathrm{ml} 2.5 \%(\mathrm{v} / \mathrm{v})$ concentrated $\mathrm{H}_{2} \mathrm{SO}_{4}$ in acetic anhydride and heated to $60{ }^{\circ} \mathrm{C}$ for $10 \mathrm{~min}$, then cooled in ice. Water was added cautiously until the liquid was immiscible with chloroform. This acetylation procedure, described by Oades (1967), obviates the need for prior removal of borate from the mixture by repeated evaporation to dryness with methanolic $\mathrm{HCl}$. The alditol acetates were extracted in three successive portions of chloroform and the combined chloroform extracts evaporated to dryness with nitrogen in a tapered glass centrifuge tube and stored at $-20^{\circ} \mathrm{C}$. Standard sugars and a reagent blank were simultaneously subjected to the entire procedure; but as a control on the destruction of glucuronic acid, this sugar was also reduced and acetylated without exposure to acid hydrolysis conditions.

Gas-liquid chromatography (g.1.c.). The instrument used was a Varian Aerograph Series 2100 with flame ionization detector. The column was $3 \mathrm{~m}$ long, filled with Varaport 30 (Varian Aerograph) coated with $2 \cdot 2 \%(\mathrm{w} / \mathrm{w})$ ECNSS-M. Temperatures used were: column, $192{ }^{\circ} \mathrm{C}$; injector, $260{ }^{\circ} \mathrm{C}$; detector, $270{ }^{\circ} \mathrm{C}$. Gas flow rates were checked at: $\mathrm{N}_{2}, 50 \mathrm{ml} / \mathrm{min}$; air, $300 \mathrm{ml} / \mathrm{min} ; \mathrm{H}_{2}, 30 \mathrm{ml} / \mathrm{min}$. The residues in the tapered tubes were dissolved in $100 \mu \mathrm{l}$ acetone and $\mathrm{I} \mu \mathrm{l}$ of this was injected into the column. An attenuation factor of $64 \times 10^{-11}$ generally gave on-scale readings.

\section{RESULTS AND DISCUSSION}

Unpurified exopolysaccharide of both species grown on yeast mannitol broth showed a peak at the retention time for mannose, but this was completely removed by purification and avoided by the use of the defined medium (Table I). The probability of yeast mannan being the source of mannose in exopolysaccharides from yeast mannitol medium was further indicated by the finding of this sugar in the hydrolysate of the precipitated gum obtained from the supernatant of $R$. meliloti SU47 grown on defined medium with glucose, to which uninoculated yeast mannitol broth had been added immediately before centrifugation and alcohol precipitation. The characteristically low yield of exopolysaccharide from SU47 could in itself explain the high percentage of mannose reported for this strain, since a co-precipitating yeast mannan would constitute a higher proportion of the total.

We conclude from these analyses that great attention should be paid both to the growth medium, the method of preparation and the purification of exopolysaccharides in surveys of the constituents of these compounds in fast- or slow-growing rhizobia. With the highly sensitive methods of analysis now available, misleading results will readily be obtained from crude products of an undefined medium.

Some comment should also be made on the difficulty we have experienced in the detection of glucuronic acid by the g.l.c. technique. Anaerobic conditions during hydrolysis and a 
Table I. Occurrence of hexoses in Rhizobium exopolysaccharides

\begin{tabular}{|c|c|c|c|c|c|}
\hline & & & \multicolumn{3}{|c|}{$\begin{array}{l}\text { Retention time of hexose alditol } \\
\text { acetate derivatives relative to } \\
\text { glucose standard }\end{array}$} \\
\hline \multicolumn{3}{|c|}{ Exopolysaccharide } & & & \\
\hline Strain & Medium & Treatment & I. O & 0.89 & 0.76 \\
\hline $\begin{array}{l}\text { R. trifolii } \\
\text { TAI }\end{array}$ & $\begin{array}{l}\text { Yeast mannitol broth } \\
\text { Defined medium with glucose or mannitol }\end{array}$ & $\begin{array}{l}\text { Unpurified* } \\
\text { Purified } \dagger \\
\text { Unpurified }\end{array}$ & $\begin{array}{l}1 \cdot 00 \\
1 \cdot 00 \\
1 \cdot 00\end{array}$ & $\begin{array}{l}0.85 \\
0.89 \\
0.88\end{array}$ & $\underline{0.76}$ \\
\hline $\begin{array}{l}\text { R. meliloti } \\
\text { SU47 }\end{array}$ & $\begin{array}{l}\text { Yeast mannitol broth } \\
\text { Defined medium with glucose or mannitol } \\
\text { Defined medium with glucose }+ \text { sterile } \\
\text { yeast mannitol broth }\end{array}$ & $\begin{array}{l}\text { Unpurified } \\
\text { Purified } \\
\text { Unpurified } \\
\text { Unpurified }\end{array}$ & $\begin{array}{l}0.99 \\
0.99 \\
1 \cdot 00 \\
1 \cdot 00\end{array}$ & $\begin{array}{l}0.85 \\
0.87 \\
0.88 \\
0.88\end{array}$ & $\frac{0 \cdot 77}{-}$ \\
\hline
\end{tabular}

minimum of preparative steps involving heat seemed essential for an end product to be detected after reduction and acetylation. About $96 \%$ of the original amount of free glucuronic acid (as judged by peak areas) was destroyed when subjected to the hydrolysis step, necessitating the use of unhydrolysed standards. Glucuronic acid was more readily detected in the gum ( $R$. trifolii TAI), though it was doubtless also partly destroyed during hydrolysis. Moreover, the method of acetylation was responsible for widely differing peaks. With the more usual acetylating procedure (acetic anhydride:pyridine, I: I (v/v); I $5 \mathrm{~min}$; I00 ${ }^{\circ} \mathrm{C}$ ), a large peak was observed for the glucuronic acid standard, having a retention time of about 0.86 that of glucose and therefore not resolved from galactose (retention time 0.89 ). When the concentrated sulphuric acid : acetic anhydride method was used for acetylation, this peak was entirely replaced by the two small peaks in the pentose region of the chart (retention times 0.34 and 0.46 of glucose) where, in the present instance, there is no confusion with peaks representing other constituents of the gum.

This investigation has been supported by the Australian Research Grants Committee and the Wheat Industry Research Council.

\section{REFERENCES}

Armarger, N., Obaton, M. \& Blachère, H. (1967). Polysaccharides extracellulaires de Rhizobium meliloti. Canadian Journal of Microbiology 13, 99-105.

Bailey, R. W., Greenwood, R. M. \& Craig, A. (1971). Extracellular polysaccharides of Rhizobium strains associated with Lotus species. Journal of General Microbiology 65, 31 5-325.

Björndal, H., Erbing, C., Lindberg, G., FÅhraeus, G. \& LjungGren, H. (I97I). Studies on an extracellular polysaccharide from Rhizobium meliloti. Acta chemica scandinavica 25, 1281-1 286.

Clapp, C. E. \& Davis, R. J. (1970). Properties of extracellular polysaccharides from Rhizobium. Soil Biology and Biochemistry 2, 109-1 17.

Dudman, W. F. (1964). Immune diffusion analysis of the extracellular soluble antigens of two strains of Rhizobium meliloti. Journal of Bacteriology 88, 782-794.

Dudman, W. F. \& Heidelberger, M. (1969). Immunochemistry of newly found substituents of polysaccharides of Rhizobium species. Science, New York 164, 954-955.

HePPER, C. M. (1972). Composition of extracellular polysaccharides of Rhizobium trifolii. Antonie van Leeuwenhoek 38, 437-445.

Humphrey, B. A. \& VinCENT, J. M. (1959). Extracellular polysaccharides of Rhizobium. Journal of General Microbiology 21, 477-484. 
OADES, J. M. (1967). Gas-liquid chromatography of alditol acetates and its application to the analysis of sugars in complex hydrolysates. Journal of Chromatography 28, 246-252.

Sevag, M. G., Lackman, D. B. \& Smollens, J. (1938). The isolation of the components of streptococcal nucleoproteins in serologically active form. Journal of Biological Chemistry 124, 425-436.

VINCENT, J. M. (1962). Influence of calcium and magnesium on the growth of Rhizobium. Journal of General Microbiology 28, 653-663.

Vincent, J. M. (1970). In A Manual for the Practical Study of Root-nodule Bacteria, p. 3. IBP Handbook no. I5. Oxford and Edinburgh: Blackwell Scientific Publications.

ZeVEnhuisen, L.P.T. M. (1971). Chemical composition of exopolysaccharides of Rhizobium and Agrobacterium. Journal of General Microbiology 68, 239-243. 